Pure Appl. Bio., 3(2): 66-71, June-2014.

\title{
Parental Bias in Segregation Distortion of RAPD Markers from Solanum Anther-Derived Plants
}

\author{
A. Naseer Aziz ${ }^{*}$ \\ Department of Agricultural and Environmental Science, College of Agriculture, Human and Natural Sciences, \\ Tennessee State University, 3500 John A. Merritt Boulevard, Nashville, TN 37013, USA. \\ *Corresponding author: E-mail: aaziz@tnstate.edu, \\ Phone \# (615)963-1595, fax \# (615)963-1557
}

\begin{abstract}
A diploid Solanum clone 9507-04 was used to grow anther-derived plantlets that were putatively monoploid. Sixteen RAPD primers were used to observe the RAPD profiles from anther-donor and anther-derived materials. Atotal of 56 RAPD markers were scored and each marker was identified according to the primer's designation and size (kilo base pairs) of the amplified fragment. Of 56 RAPD markers assayed, 44.6\% did not follow the expected 1:1 Me ndelian segregation $\left(\chi^{2}>4.26, \mathrm{P}<0.05\right)$ in the anther-derived progeny. The selected six morphological traits also segregated in anther-derived plants including the nine that retained 3-4 of the parental leaf characters. The 12 distortion-causing RAPD markers $(\chi 2=8.89-17.64, \mathrm{P}<0.003)$ with above $84 \%$ presence in the progeny were retained in all above nine plants. Such preference of parental markers in potato anther-derived progeny may indicate a linkage with androgenesis.
\end{abstract}

Key words: Anther culture, parental-type, polymorphism, potato.

\section{Introduction}

Anther-culture of diploid potatoes can be used for the production of monoploid plants $[1,2,3]$. However, the gametic cells respond variedly to the culture conditions leading to different levels of tissue development in anther-derived progeny $[1,4]$. Such variations in anther-culture response are attributed to actions of gametophytic active genes, sporophytic active genes, or gameto-sporophytic interactions [5].Therefore, potato anther-derived progeny has been reported to give distorted segregation in 29 to $70 \%$ of the molecular markers [6,7,8]. Gamete selection, (sub) lethal alleles, anther-culture technique, and regeneration pressure have been suggested as possible causes of distorted segregation of molecular markers [9,10].RAPD (random amplified polymorphic DNA) markers can be used without any prior genome information for the genetic analyses of anther-derived monoploids $[11,12]$. The issue of dominant inheritance of RAPD markers [13] can be circumvented by using gametophytic tissue, since a heterozygous genotype (for an allelic pair) segregates into gametes carrying dominant and recessive markers [14]. RAPDs have been markers of choice for genetic analyses of tissue cultured potatoes $[15,16,17]$. This report aims to examine the segregation of some RAPD markers and morphological traits in anther-derived progeny of the diploid 9507-04 parent.

\section{Materials and methods \\ Plant materials}

The diploid Solanum clone 9507-04 (50\% S. tuberosum and 50\% wild: S. chacoense, Argentinian wild potato species) was kindly provided by Dr. Hielke De Jong, Potato Research Centre, Agriculture and Agri-Food Canada. Solanum clone 9507-04 produced abundant anther-derived plantlets under anther-culture conditions of Aziz et al. [18]. The leaves silhouette and amount of anthocyanin as well as morphological features of primary/terminal leaflet were identified as described [19, 20, 21]. The putative monoploid anther-derived material from the clone 9507-04 was chosen for the RAPD analysis.

\section{DNA isolation and amplification}

Up to $50 \mathrm{mg}$ of the leaf tissue was homogenized in $300 \mu l$ of the extraction buffer [22] with a pellet pestle (Mandel Scientific Co.). The mixture was incubated at $65^{\circ} \mathrm{C}$ for $90 \mathrm{~min}$ followed by two chloroform/isoamyl alcohol (24:1) extractions. The DNA was precipitated by an equal volume of cold isopropanol and resuspended in $30 \mu \mathrm{l}$ of distilled water. Quantification of the DNA preparation was made by comparing with DNA Mass Ladder (Life Technologies) under gel electrophoresis conditions.

Ten ng DNA template or distilled sterile water as control was used in polymerase chain reaction (PCR) mixtures. The PCR mixture $(25 \mu \mathrm{l}$ in $0.2 \mathrm{ml}$ tube $)$ also 
included $0.2 \mu \mathrm{M}$ primer, $50 \mu \mathrm{M}$ each of dATP, dCTP, dGTP, dTTP, 1 unit Ampli-Taq DNA polymerase (Perkin Elmer) and $1 \mathrm{X}$ PCR buffer $(10 \mathrm{mM}$ TrisHCl, $\mathrm{pH} 8.3,50 \mathrm{mM} \mathrm{KCl}, 2 \mathrm{mM} \mathrm{MgCl}_{2}, 0.001 \%$ gelatin) that was overlaid with a drop of fresh mineral oil. After an initial four min denaturation at $94^{\circ} \mathrm{C}$ in a PTC- 100 Thermal Controller (MJ Research), the amplification reactions were carried out using 45 cycles (default ramp time) of 1 min denaturation at $94^{\circ} \mathrm{C}, 1 \mathrm{~min}$ annealing at $36^{\circ} \mathrm{C}$, and $2 \mathrm{~min}$ extension at $72^{\circ} \mathrm{C}$. All PCR products were then subjected to 10 min extension at $72^{\circ} \mathrm{C}$ followed by soak at $4^{\circ} \mathrm{C}$ until recovery. In each set of amplification reactions one control was a PCR mixture excluding any template whilst the other contained DNA from the anther donor (Figure 1).

The PCR products ( $10 \mu$ l of the reaction mixtures) were separated by electrophoresis $\left(3.5 \mathrm{Vcm}^{-1}\right.$ for $\left.3 \mathrm{~h}\right)$ on $1.4 \%$ agarose gel stained with ethidium bromide $\left(0.5 \mu \mathrm{gml}^{-1}\right)$ in $0.5 \mathrm{X}$ TBE $(0.045 \mathrm{M}$ Tris, $0.045 \mathrm{M}$ Boric acid, 0.001M EDTA) buffer. The gels were photographed using a UV transilluminator (Fotodyne, Inc.). Sizes of the RAPD markers were determined by comparing with a DNA Mass Ladder.

\section{Statistical analysis}

Reproducible RAPD-PCR products in the parent were used as markers. Parental RAPD markers were then scored for presence or absence in the anther-derived progeny. For each RAPD marker goodness-of-fit to expected segregation of 1:1 was tested by Chi-square analysis using SYSTAT version 7.0 (SPSS Inc., USA). Segregation ratios that differed from the expected value (significant at $\mathrm{P}=0.05$ or less) were classified as distorted.

\section{Results and discussion}

\section{RAPD markers' identification}

Sixteen RAPD primers (Table 1) reported to generate polymorphic markers from potato $[22,23,3,24,25,8]$ and an additional primer OPH-08 (selected for producing a segregation pattern) were used in this study. The primers from University of British Columbia (UBC) and Eurofins MWG Operon (OP) have recently been used for genetic diversity studies [26].These 16 primers generated 56 reproducible RAPD markers from anther-donor clone 9507-04 (Table 1). A similar number of scorable markers have been reported for the same RAPD primers in genetic identity studies of potato[ $22,23,3,24,25,8]$. Complete documentation of the sizes of RAPD markers was not reported by the above authors; therefore, accurate comparison for all the RAPD markers was not possible. The present study confirmed the reports of
Sosinski and Douches [25] in which primer OPA-02 reproduced RAPD markers with molecular sizes of approximately $0.67 \mathrm{kbp}, 0.76 \mathrm{kbp}, 0.93 \mathrm{kbp}$ and 1.11 kbp. Primer UBC131 reproduced the markers of approximately $1.03 \mathrm{kbp}$ and $1.55 \mathrm{kbp}$ sizes similar to those reported under PCR conditions of Demeke et al. [22]. A nomenclature of RAPD markers based on their molecular size and primer name has been proposed to standardize any RAPD assessment of germplasm [23]. Their recommended nomenclature of RAPDs was used in this study. The 56 RAPD markers in this study were designated according to the name of primer and size (kbp) of the amplified fragment (Table 1). Therefore, these markers can conveniently be used for a standard comparison with RAPD profiles from other related genotypes.

\section{Leaf morphology of anther-derived plants}

The mature leaves of potato are described as a pinnately compound [21] and six of the leaf characters were used to identify progeny of anther-donor parent (Table 2). The leaf morphological traits of parent segregated in anther-derived plants thus differing from each other. The leaf silhouette was either open or medium. Amount of leaf anthocyanin and pubescence varied from light to medium or heavy. The shape of terminal or primary leaflet was found elliptical, narrowly ovate or broadly ovate. The tip of these leaflet were classified as acuminate, acute or cuspidate. Also the leaflet bases were found as cordate, obtuse, acute or truncate. Such morphological differences reflected the segregation of parental and non-parental type genetic characters in the progeny. The anther-derived progeny revealed assorted non-parental leaf traits. Androgenesis has been reported to induce genomic changes in potato [27]. Out of the 20 anther-derived plants generated, nine were found similar to the parent. These plants showed retention of three or four of the parental leaf characters (Table 2).Segregation studies in monoploid regenerants would also be useful in genetic analysis since they are expected to be developed from individual microspores. Therefore, such studies can also be used to identify extra-chromosomal and/or physiological factors affecting the survival of monoploids or dihaploid.

\section{Segregation distortion of RAPD markers}

Parental RAPD markers were scored for presence or absence of a DNA band in the anther-derived progeny. Segregation of the RAPD markers was examined against the expected 1:1 ratio by Chi-square analysis. Of 56 markers assayed (Table 1), 44.6\% did not segregate according to expected 1:1 Mendelian ratio 
$\left(\chi^{2} \geq 4.26, \quad \mathrm{P} \leq 0.05\right)$. Anther-derived progeny is reported to give much higher percentage of skewed markers as compared to that from the populations of selfed progenies [7]. Segregation distortion can be caused by the gamete selection, i.e., only a few selected microspores may survive in the mature anthers [28]. During anther culture, the genotypes which are culture-responsive could be further selected, causing an even greater distortion in the segregation of molecular markers [7,10]. The marker UBC291-1.4 showed a distorted ratio in anther-derived progeny for 'presence of band: absence of band' $=21: 2\left(\chi^{2}=15.696\right.$, $\mathrm{P}<0.005)$. Interestingly, the same marker also showed the distorted segregation in the pollen population [29]. It appears that UBC291-1.40 is selected against during pollen maturation and selected for anther culture. This marker therefore may be related to alleles essential for the survival of culture responsive microspores.

Segregation distortion can occur due to the selection pressure in the pollen maturation process, and additional selection pressures during anther-culture conditions may contribute further to the distorted segregation of the markers. From 25 distorted markers (Table 1) 13 RAPDs were either unevenly present or absent in anther-derived progeny $(\chi 2=4.26-11.56, \quad \mathrm{P}=0.001-0.05)$. Non-random chromosome segregation during meiosis is another possible explanation for the distorted segregation observed [30].The other 12 RAPD markers showed distorted segregation by being retained in more than $84 \%$ of the progeny ( $\chi 2=8.89-17.64, \mathrm{P}<0.003)$. Thus being distortion-causers [31], most of these RAPDs have been used as seed-markers for a linkage mapping approach. Incidentally this group of 12 distortion-causing markers was found intact in the nine plants (Table 2) having mostly parental traits. Segregation distortion during doubled haploid production is likely to be due to a range of factors including selection during the process of gamete culture and plantlet regeneration [32].Simultaneous presence of group parental markers in anther-derived progeny reported in this study may indicate a linkage with androgenesis in potatoes. Androgenic fitness has an important role in the prevalence of markers with segregation distortion and linkage of such markers to specific genes controlling in vitro androgenesis[ 33]. Further studies of segregation of molecular markers at various pollen maturation and microspore regeneration stages would help to identify the genetic factors involved in these processes.

Table 1: Analysis of the random amplified polymorphic DNA (RAPD) markers for 1:1 segregation in the anther-deri ved progeny of Solanum clone 9507-04.

RAPD markers designation*

OPA002-1.11, OPA005-0.61, OPB010-0.57, OPB010-0.65, OPB010-1.60, OPC007-0.58, OPC007-0.87, OPC013-0.36, OPC013-0.93, OPC013-1.16, OPC013-2.24, OPC013-6.53, OPC015-0.63, OPC015-0.70, OPC015-0.78, OPC015-1.00, OPG015-0.26, OPG015-0.83, OPG015-1.47, OPH008-0.92, UBC131-1.25, UBC184-1.15, UBC291-0.40, UBC308-2.00, UBC504-0.86, UBC504-0.92, UBC504-1.50, UBC504-1.98, UBC504-2.24,UBC559-1.14, UBC559-2.00

OPA002-0.93, OPC007-1.84, OPC013-0.56, OPC015-0.71, OPC015-1.00, OPC015-1.16, UBC131-1.03, UBC131-1.55, UBC184-0.59, UBC291-0.67, UBC308-0.67, UBC504-1.03, UBC533-0.93

OPA002-0.67, OPA002-0.76, ОРB010-0.36, OPB010-0.96, OPC015-0.39, OPC015-1.47, OPH008-1.00, OPH008-1.26, UBC153-0.64,UBC291-1.14, UBC308-0.96, UBC533-1.27

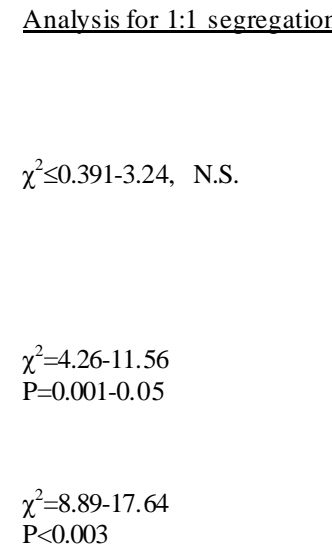

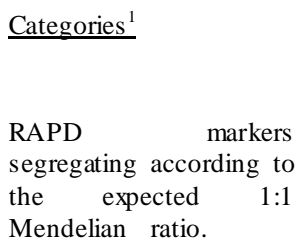

RAPD markers showing distortion from the expected 1:1 segregation

Distortion causers with $>84 \%$ presence in monolploids

*The letters on left side of the hyphen represent the name of the RAPD primer (UBC/OP); dig its on the right show the size (kbp) of the amplified fragment.

${ }^{1}$ Categories for RAPD markers are based on Chi-square test for 1:1 segregation of the parental DNA band presence vs. absence in the progeny. 


\begin{tabular}{|c|c|c|c|c|c|c|}
\hline \multirow[b]{2}{*}{ Plants } & \multirow[b]{2}{*}{ Leaf silhouette } & \multicolumn{3}{|c|}{ Terminal/primary leaflet: } & \multirow[b]{2}{*}{ Anthocyanin in leaves } & \multirow[b]{2}{*}{ Leaf pubescence } \\
\hline & & Shape & Shape of Tip & $\begin{array}{l}\text { Shape of } \\
\text { base }\end{array}$ & & \\
\hline Parent & Open & $\begin{array}{l}\text { Narro wly } \\
\text { ovate }\end{array}$ & Acuminate & Cordate & Light & Medium \\
\hline 1 & Open & $\begin{array}{l}\text { Narro wly } \\
\text { ovate }\end{array}$ & Cuspidate & Obtuse & Heavy & Medium \\
\hline 2 & Open & $\begin{array}{l}\text { Narro wly } \\
\text { ovate }\end{array}$ & Acuminate & Acute & Medium & Medium \\
\hline 3 & Open & $\begin{array}{l}\text { Narro wly } \\
\text { ovate }\end{array}$ & Acuminate & Obtuse & Medium & Medium \\
\hline 4 & Open & $\begin{array}{l}\text { Narro wly } \\
\text { ovate }\end{array}$ & Acuminate & Acute & Medium & Medium \\
\hline 5 & Medium & $\begin{array}{l}\text { Narro wly } \\
\text { ovate }\end{array}$ & Acute & Cordate & Light & Light \\
\hline 6 & Open & $\begin{array}{l}\text { Narro wly } \\
\text { ovate }\end{array}$ & Acuminate & Obtuse & Light & Light \\
\hline 7 & Open & $\begin{array}{l}\text { Narro wly } \\
\text { ovate }\end{array}$ & Acute & Obtuse & Medium & Medium \\
\hline 8 & Open & $\begin{array}{l}\text { Narro wly } \\
\text { ovate }\end{array}$ & Acuminate & Obtuse & Heavy & Medium \\
\hline 9 & Open & $\begin{array}{l}\text { Narro wly } \\
\text { ovate }\end{array}$ & Acuminate & Obtuse & Heavy & Light \\
\hline
\end{tabular}

* The segregating leaf morphological characters $[19,20,21]$ of parent in the nine anther-derived plants that showed retention of $3-4$ traits of the anther donor.

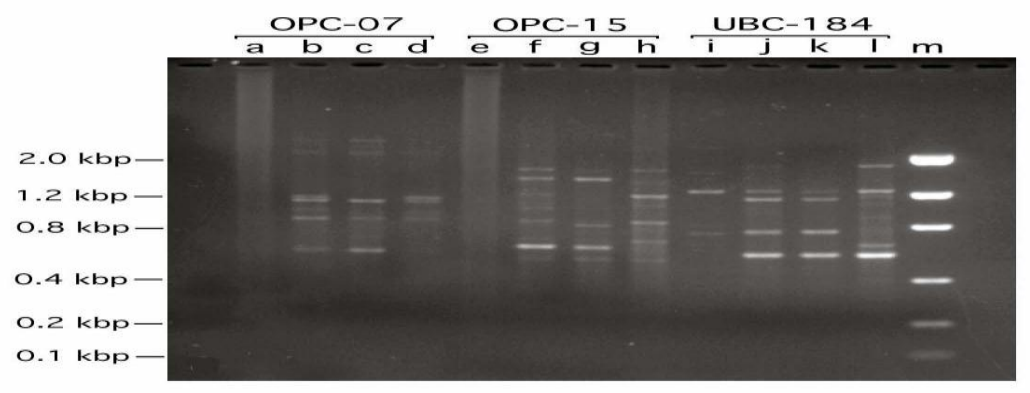

Figure 1: Groups of four lanes showing PCR a mplifications with a rando m a mplified poly morphic DNA (RAPD) primers: the two lanes at the extreme left present the template free reactions and the DNA profiles of the parental clone $9507-04$ respectively; the two lanes at the extreme right show the segregation of parental RAPD markers in the selected anther-derived progenies. Lanes a-d, primer OPC-07; lanes e- f, primer OPC-15; lanes i to 1, primer UBC184. Lane m presents a $2.0 \mathrm{kbp}(200 \mathrm{ng})$ to $0.1 \mathrm{kbp}$ (10 ng) DNA Mass Ladder (Life Technologies). At the left margin relative positions of the DNA markers are shown. The parental RAPD markers were identified by primer name and their sizes (kbp), to be scored as present or absentin the anther derived progeny. 


\section{Acknowledgments}

The author acknowledges the greenhouse maintenance of the plants by Andrew Gardner and Steven Allaby. Thanks are due to L. Katheryn Douglass for tissue culture suggestions, Susan Oborn for computer analysis suggestions, Coral Curtis for flow cytometer operation, and Roger Smith for photographic printing. Technical assistance by Drs. Janet E.A. Seabrook and George C. C. Tai is also appreciated. This research was supported by the Department of Biology, University of New Brunswick and Agriculture \&Agri-Food Canada.

\section{References}

1. Heberle Bors, E. (1985). In vitro haploid formation from pollen: a critical review. Theoretical and Applied Genetics 71: 361-374.

2. Meyer, R., F. Salamini, and H. Uhrig. (1993). Isolation and characterization of potato diploid clones generating a high frequency of monohaploid or homozygous diploid androgenic plants. Theoretical and Applied Genetics 85: 905-912.

3. Rokka, V.-M., J.P.T. Valkonen, and E. Pehu. (1995). Production and characterization of haploids derived from somatic hybrids between Solanum brevidens and $S$. tuberosum through anther culture. Plant Science 112:85-95.

4. Uhrig, H. (1985). Genetic selection and liquid medium conditions improve the yield of androgenetic plants from diploid potatoes. Theoretical and Applied Genetics 71: 455-460.

5. Cordewener, J.H.G., J.B.M. Custers, H.J.M.Dons, and M.M.V.L. Campagne. (1996). Molecular and biochemical events during the induction of microspore embryogenesis. In In vitro haploid production in higher plants, ed S.M. Jain; S.K. Sopory and R.E. Veilleux, 111 124. Kluwer Academic Publishers, Netherlands.

6. Ravichandran, V., and R.E. Veilleux. (1996). Application of RAPD markers to study segregation ratios in a monoploid potato family. American Potato Journal 73: 379-380.

7. Rivard, S.R., M. Cappadocia, and B.S. Landry. (1996). A comparison of RFLP maps based on anther culture derived, selfed, and hybrid progenies of Solanum chacoense. Genome 39:611-621.

8. Veilleux, R.E., L.Y. Shen, and M.M. Paz. (1995). Analysis of the genetic composition of anther-derived potato by randomly amplified polymorphic DNA and simple sequence repeats. Genome 38: 1153-1162.
9. Xu, Y., L. Zhu, J. Xio, N. Huang, and S.R. McCouch. 1997. Chromosomal regions associated with segregation distortion of molecular markers in $\mathrm{F}_{2}$, backcross, double haploid, and recombinant inbred populations in rice (Oryza sativa L.). Molecular and General Genetics 253: 535-545.

10. Yamagishi, M., M. Yano, Y. Fukuta, K. Fukui, M. Otani, and T. Shimada. 1996. Distorted segregation of RFLP markers in regenerated plants derived from anther culture of an $\mathrm{F}_{1}$ hybrid of rice. Genes and Genetic Systems 71:37-41.

11. Landry, B.S. (1993). DNA mapping in plants. In Methods in plant molecular biology and biotechnolgy, ed. B.R. Glick, and J.E. Thompson, 269-285. CRC Press, Boca Raton, USA.

12. Milbourne, D., R. Meyer, J.E. Bradshaw, E. Baird, N. Bonar, J. Provan, W.Powell, and R. Waugh. (1997). Comparison of PCR-based marker systems for the analysis of genetic relationships in cultivated potato. Molecular Breeding 3: 127-136.

13. Williams, J.G.K., A.R. Kubelik, K.J. Livak, J.A. Rafalski, and S.V. Tingey. (1990). DNA polymorphisms amplified by arbitrary primers are useful as genetic markers. Nucleic Acids Research 18: 6531-6535.

14. Horn, P., and A. Rafalski. (1992). Non-destructive RAPD genetic diagnostics of microspore-derived Brassica embryos. Plant Molecular Biology Reporter 10: 285-293.

15. Afrasiab, H., and J. Iqba. (2012). Biochemical and molecular characterization of somaclonal variants and induced mutants of potato (Solanum tuberosum L.) cv. Desiree. Pakistan Journal of Botany 44: 1503-1508.

16. Saker, M.M., T.A.A. Moussa, N.Z. Heikal, A.H.A. Abo ELLil, and R.M.H. Abdel-Rahman, (2012). Selection of an efficient in vitro micropropagation and regeneration system for potato (Solanumtuberosum L.) cultivar Desirée. African Journal of Biotechnology 11: 16388-16404.

17. Tiwari, J.K., D. Poonam, Sarkar, S.K. Pandey, J. Gopal, and S.R. Kumar. 2010. Molecular and morphological characterization of somatic hybrids between Solanumtuberosum L. and $S$. etuberosumLindl.Plant Cell, Tissue and Organ Culture 103: 175-187.

18. Aziz, A.N.,J.E.A. Seabrook,G.C.C. Tai, and H. De Jong. (1999). Screening diploid Solanum genotypes responsive to anther culture conditions and ploidy assessment of anther-derived roots and plantlets. American Potato Journal. 76:9-16. 
19. Canadian Food Inspection Agency. (2013). Potato: A91556-1W. Crop Reports. http://www.inspection.gc.ca/english/plaveg/pbrpo v/cropreport/pot/app00004811e.shtml. Accessed 24 April 2013]

20. Cutter, E.G. (1978). Structure and development of the potato plant. In The potato crop: The scientific basis for improvement, ed. P.M. Harris, 70-152. Chapman and Hall Ltd, London, UK.

21. Cox, A.E. (1967). The potato: A practical and scientific guide. W. H. \& L. Collingridge Ltd, London, UK.

22. Demeke, T., L.M. Kawchuk, and D.R. Lynch. (1993). Identification of potato cultivars and clonal variants by random amplified polymorphic DNA analysis. American Potato Journal 70: 561-570

23. Demeke, T., D.R. Lynch, L.M. Kawchuk, C.C. Kozub, and J.D. Armstrong. (1996). Genetic diversity of potato determined by random amplified polymorphic DNA analysis. Plant Cell Reports 15:662-667.

24. Singsit, C., and P. Ozias-Akins. (1993). Genetic variation in monoploids of diploid potatoes and detection of clone-specific random amplified polymorphic DNA markers. Plant Cell Reports 12: 144-148.

25. Sosinski, B., and D.S. Douches. (1996). Using polymerase chain reaction-based DNA amplification to fingerprint North American potato cultivars. HortScience 31: 130-133.

26. EL-Amin, H.K.A. and N.B. Hamza. (2013). Phylogenetic Diversity of Sorghum bicolor (L.) Moench Accessions from Different Regions in Sudan. American Journal of Biochemistry and Molecular Biology 3: 127-134.
27. Sharma, S., D. Sarkar, and S.K. Pandey. (2010). Phenotypic characterization and nuclear microsatellite analysis reveal genomic changes and rearrangements underlying androgenesis in tetraploid potatoes (Solanum tuberosum L.). Euphytica 171:313-326.

28. Cadalen, T., C. Boeuf, S. Bernard, and M. Bernard. (1997). An intervarietal molecular marker map in Triticum aestivum L. Em. Thell. and comparison with a map from a wide cross. Theoretical and Applied Genetics 94: 367-377.

29. Aziz, A.N., J.E.A. Seabrook, and G.C.C. Tai. (1999). Amplification of RAPD Markers from Individual Pollen Grains of a Diploid Solanum Clone 9507-04. American Potato Journal 76: 179-182.

30. Cai, X., and S.S Xu. (2007). Meiosis-driven genome variation in plants. Current Genomics 8: $151-161$.

31. Tai, G.C.C.,J.E.A. Seabrook, and A.N Aziz. (2000). Linkage analysis of anther-derived monoploids showing distorted segregation of molecular markers. Theoretical and Applied Genetics 101: 126-130.

32. Pathirana, R., T. Frew, D. Hedderley, G. Timmerman-Vaughan, and E. Morgan. (2011). Haploid and doubled haploid plants from developing male and female gametes of Gentian atriflora. Plant Cell Reports 30: 1055-1065.

33. Foisset, N., R. Delourme, P. Barret, N. Hubert, B.S. Landry, and M. Renard. (1996). Molecular-mapping analysis in Brassica napus using isozyme, RAPD and RFLP markers on a doubled-haploid progeny. Theoretical and Applied Genetics 93: 1017-1025. 